\title{
Traces of the Unconscious in Language
}

\author{
M. Zuhal Bilik ${ }^{1}$, Eylül C. Hekimoğlu, \& Faruk Gençöz \\ Middle East Technical University
}

\begin{abstract}
The significance of language in clinical practice first emerged with the Anna O. case, a study by Freud. Lacan went on to support Freud's findings. Through the Back to Freud movement, Lacan proved language to be crucial from theoretical and clinical perspectives. According to Lacan, the name of the father in the language used by the mother functions as a signifier for the mother's desire. It corresponds to the first repression and enters the symbolic register. It refers to Lacan's famous statement 'Unconscious is structured like a language'. As such, in his theory, Lacan actively uses the concepts of signifier, signified, metaphor and metonymy and offers new interpretations of these concepts. Therefore, to study the unconscious, working with language is the main method. However, because of repression, the unconscious can only be studied through the traces it shows in language. In this article, traces of the unconscious in language are explained using clinical examples. Clarifications are provided as to how traces of the unconscious can be studied analytically.
\end{abstract}

\section{Introduction}

The main work principle in psychoanalysis is to study the function of speech. This logic was based on Freud's work, however, over time it suffered from erosion in the field of psychoanalysis (Lacan, 2006a). This paper focuses on linguistic logic, how to use language in psychoanalysis and the theoretical background of language in psychoanalysis.

Psychoanalysis is rooted in 1890's when Freud started accepting hysterical patients, since he could not earn well from his neurology specialization (Perron, 2017). In early periods of accepting hysterical patients, Freud tried hydrotherapy and electrotherapy methods. However, these methods did not yield any results. After attending Charcot's hypnosis lessons in 1885 in France, Freud decided to use hypnosis. Nevertheless, hypnosis did not offer a sustainable solution. He realized that hypnotized patients initially overcame their symptoms, but after a while, either the same symptoms re-appeared or different symptoms emerged. Freud was stuck until he remembered about Anna O., one of Breuer's patients (Freud, 1910). Anna O. was a young educated woman from a wealthy family. She had developed paralysis on various limbs. After her father fell ill, she gradually lost her ability to speak. Breuer initially tried hypnosis to relieve Anna's symptoms. During the first hypnosis, Anna uttered a meaningless sentence, containing words from five different languages. After this attempt, Breuer stopped telling Anna what to do during hypnosis and started encouraging her to talk. Although Anna called this method a talking cure, the foundations of the free association method were laid. The reason Anna called this method a talking cure was, of course, the relationship between language and the unconscious. While hypnotized, Anna O. remembered several events relating to the onset of her symptoms, including emotional burden. When she recounted these events, her symptoms disappeared. For example, Anna did not drink water for approximately one year. She drank other types of beverages. Although she was thirsty and brought the water closer to her lips, she refused to drink when she realized it was water. One day, she was under hypnosis and

\footnotetext{
${ }^{1}$ Correspondence concerning this article should be addressed to M. Zuhal Bilik, Middle East Technical University. E-mail: munevver.bilik@metu.edu.tr
}

Language and Psychoanalysis, 2021, 10 (1), 27-35. 
remembered that a dog was drinking water from the glass in the maid's room. After she expressed herself, she began to drink water again (Freud \& Breuer, 2001). In this context, Anna O's case revealed how important language is to work with the unconscious.

After Anna O's case, Freud realized that the unconscious is closely related to language. For example, in his book Everyday Life in Psychopathology, Freud recalls the occasion when he asked a woman about her son's duty in the army. The woman replied '42. Mörder', which means murder in German, whereas the correct answer should have been '42. Mörser', meaning artilleryman in German (Freud, 2002, p. 113). This observation is an example of how the unconscious emerges through language. According to Freud, this slip is an example of the repressed unconsciousness; other examples of repressed unconsciousness include bungled actions, accidents, or being forgetful (Freud, 2002).

Lacan states that, after Freud's time in early 1900's, studies on speech and language became less frequent. In the Back to Freud movement, Lacan studies parts of Freud's theories which focus on linguistics and structure, rather than focusing on ego behaviours. When describing his psychoanalytic studies, Lacan states that he studied the function of speech rather than the function of ego. According to Lacan, ego studies inflate the subject's ego, thus increasing the subject's levels of frustration and aggression. Lacan argues that the analytic process allows an analysis of the function of speech, in order to study the unconscious desire. As such, according to Lacan, there is nothing in the unconscious except Parletré, which means speaking presence (Lacan, 2006a). Since the unconsciousness is associated with language, the only way of studying the unconscious is working with the language. Psychoanalysis is known as a talking cure, although the relationship between language and psychoanalysis have only found real meaning thanks to Lacan. Theoretical information about how language is studied in psychoanalysis and clinical implementations are discussed in the following section.

\section{Lacanian Theoretical Perspective}

Jacques Lacan gave his 3rd seminar, titled 'The Psychoses', during the years 1955-1956. In this seminar, he explored the symbolic order and the nature of language. He coined the famous definition of the relationship between the unconscious and language: 'The unconscious is structured like a language'. (Lacan, 1993, p. 119). This definition can be studied in depth.

In his article The Function and Field of Speech and Language, published in his book Écrits, Lacan studies the relationship between the unconscious and language. Lacan states that the unconscious forms part of the subject's history and that the unconscious represents a gap, a censored chapter. Lacan argues that nonetheless, the subjective truth can be re-discovered. As such, speech is the subject's attempt to rediscover the truth. When Anna O.'s case is analysed in this light, according to Lacan, the body contains the truth. When the body is verbalized, it is unlocked like a password and the truth surfaces. Anna O.'s traumatic experience (the dog drinking water from a cup), when verbalized, results in the disappearance of her symptoms (Anna O. manages to drink water again). This behaviour resulted in the discovery that a traumatic event can cause illness for the hysteric subject. The concept of verbalization gains importance; according to Lacan, verbalization results in the patient remembering and describing his past traumatic experiences while conscious (when not hypnotized). The crucial factor is for the subject to verbalize this experience in his own language, using the culture his language operates in, and for the subject to restructure this experience while verbalizing. Thus, the subject's speech carries traces of his speech in the first years of his life and is enunciated once again. A common misconception is that the subject's verbalization is based on a lie or a

Language and Psychoanalysis, 2021, 10 (1), 27-35. 
mistake. To the contrary, the verbalization reveals the truth (Lacan, 2006a). One must then explore why the subject's mysterious, incomprehensible truth surfaces through the subject's language. According to Freud, this is related to the father's death, which throughout history has been a very dramatic event. According to Lacan, the truth's emergence through language is explained through the father's symbol (Lacan, 1993).

Lacan points out that words have existed since the beginning of humanity, and that humans use speech only because humanity is formed of symbols. In his article The Function and Field of Speech and Language in Psychoanalysis, Lacan offers a marriage-based interpretation. He explains that, in intra-subject relationships, marriage and family ties are recognized in a symbolic order. The subject accepts the incest taboo based on this signification. This incest taboo consists of the primordial order, detailed in Freud's book Totem and Taboo. The primordial exists in the domain of the surname and language; the father's surname renders the mother and child's union impossible. As such, the Name-of-the-Father signifies the oedipal taboo, enables the subject to understand the taboo and thus the subject becomes subject to the symbolic order. When the subject accepts this taboo, the Name-of-the-Father illustrates the mother's desire, leading to the creation of the paternal metaphor, which Lacan names the first metaphor (Lacan, 2006a). When this metaphor is created, the repressed desire and the unconscious are structured in a way similar to language.

According to Lacan, the fundamental basis in the subject's speech, is the fact that the subject is speaking to a listener. Only the analyst can identify the significant points illustrated by the traces of unconscious during the subject's speech. Similarly, only the analyst can give meaning to these significant points prominent in the analysand's speech. As such, in order to study the analysand's unconscious, it is essential for the analyst to understand how unconscious information surfaces during speech. In his article The Function and Field of Speech and Language in Psychoanalysis, Lacan provides several examples as to how the unconscious information surfaces through speech. Through his examples, Lacan also explains Freud's concepts of condensation and replacement, as outlined in Freud's The Interpretation of Dreams. Lacan classifies condensation as metaphor and replacement as metonymy, underlining the importance of these concepts in the subject's speech. As such, in order to study the unconscious, one must focus on paternal metaphor, which plays a role in the creation of the subjective truth (Lacan, 2006a). In order to study the unconscious, one must also focus on the structuring and surfacing of metaphors and metonymy.

In order to understand the concepts of metaphor and metonymy, one must study the concepts of signifier and signified, both of which play a role in structuring metaphor and metonymy. It is widely known that, in using the concepts of signifier and signified to explain the relationship between the unconscious and language, Lacan has been influenced by Saussure. According to Saussure, meaning is consistent between the signifier and signified. Taking a tree as an example, the relationship between a signifier tree and a signified tree is both semantic and strong. To the contrary, Lacan's perspective markedly differs from Saussure's. Lacan argues that the relationship between the signifier and signified is inconsistent, fluid and ever-changing. Thus, Lacan intervenes in Saussure's algorithm by introducing a bar. Lacan formulates the relationship between signified and signified as ' $\mathrm{S} / \mathrm{s}$ '. Instead of positing an inseparable tie between the word and the object pointed at by the word, Lacan states that there is a boundary between the signifier and signified. This boundary acts as a resisting force for the signified, preserving the meaning. Thus, as seen in the formula in Figure 1, the signifier is placed before 
the signified (Signifier/Signified). The belief that a signifier points to a fixed signified is an illusion (Lacan, 2006b).

$\frac{\mathrm{S} \text { (Signifier) }}{\mathrm{s} \text { ( signified) }}$

Figure 1. The representation of the relationship between the signifier and the signified.

According to Lacan, the signifier's most important feature is the fact that it belongs to a network of signifiers. The metaphor's meaning-generating feature is only made possible through the network of signifiers. Lacan defines a metaphor as the process by which a signifier substitutes for another signifier. During his Psychosis seminar (1955-1956), Lacan refers to Boaz, which functions as a metaphor: 'Sa garbe n'était point avare, ni haineuse' (Translation: 'His sheaf was neither stringent nor hateful'). In this example, the sheaf refers to Boaz. In this line, 'Sa garbe' ('his sheaf'), acquires its meaning by substituting with Boaz (Lacan, 1993). Without the distance placed between the subject and its characteristics, the sheaf cannot be named as 'stringent and hateful', thereby illustrating the fluidity of meaning between the signifier and signified. Lacan comments on the disconnected relationship between the signifier and signified and associates this disconnect with the nature of language, labelling the phenomenon as 'resistance to acquiring meaning'. Lacan argues that meanings cannot be created independently and are only made possible through metaphors. As such, the Name-ofthe-Father signifier exists to signify the mother's desire and also represents the incest taboo, thereby creating the paternal taboo. This metaphor acts as the primordial metaphor in the creation of a subject, thereby helping cement the meaning. Lacan labels the cementing of meaning as point de capiton, a process whereby meanings do not shift infinitely and eventually become fixed. The signified embodies the signifier's order and meaning. Despite its discreet positioning, the signifier's meaning becomes transparent by way of free associations. As such, in psychoanalysis, studying the signifiers becomes fundamental to understanding the signified (Lacan, 2006b).

Lacan explains that metaphor and metonymy are both necessary in the sense-making process and that both must be at play if meaning creation is to take place. Lacan associates Freud's metaphor concept with the concept of condensation. He associates Freud's metonymy concept with the concept of replacement. According to Lacan, metonymy is the acquisition of meaning during replacement. Lacan suggests that the signified is a metaphoric construct. On the other hand, the diachronic movement in the signifier network between one signifier to another, and the constant transfer of meaning across different signifiers, is an example of metonymy (Lacan, 2006a). Lacan uses Freud's Signorelli case, to describe the relationship between metaphor, metonymy and the unconscious (Lacan, 2002).

The Signorelli case is described as follows. Freud is with a lawyer, travelling by train to Herzogovina. The lawyer is a stranger to Freud. They discuss the customs of Turks living in Herzegovina. The topic somehow shifts to Italy and Italian paintings. Freud recommends that his new lawyer friend visit Orvieta to see the doomsday paintings. However, Freud cannot seem to remember the name of the artist who painted them. Instead of uttering the word Signorelli, the name of the painter, Freud utters the names Boticeli and Boltraffio. Lacan believes that the Signorelli name is lost in a hole. Even if the name appears to be 'forgotten', this instance is another way of 'remembering'. If so, what exactly is lost in the hole? Lacan states that it is the 'signifier' and not the 'signified' that is lost. In fact, Freud can visualize the

Language and Psychoanalysis, 2021, 10 (1), 27-35. 
doomsday paintings and the complexion of the painter, but is unable to remember the painter's name. Lacan believes that at this point, a metaphor surfaces. The network of signifiers which results from Freud forgetting Signorelli's name can be interpreted as metonymy: the signifiers Botticelli and Signorelli have similarities, since they both point to a painter. Similarly, signifiers Trafoi and Bosnian surface in relation with Boltraffio and they point to a venue. The phonetic similarity between the signifiers cannot be overlooked (Lacan, 2002).

Lacan states that no occurrence is a coincidence and that each occurrence makes sense in its own truth. As such, Lacan regards bungled actions and symptoms as metaphors (Lacan, 1966/2006a). He states that the unconscious can only operate through language. The Moebius strip is used by Lacan to describe the transition of the unconscious through language. The Moebius strip explains this transition which demonstrates that at one point in time, the conscious and the unconscious are both identical yet different (Lacan, 1998).

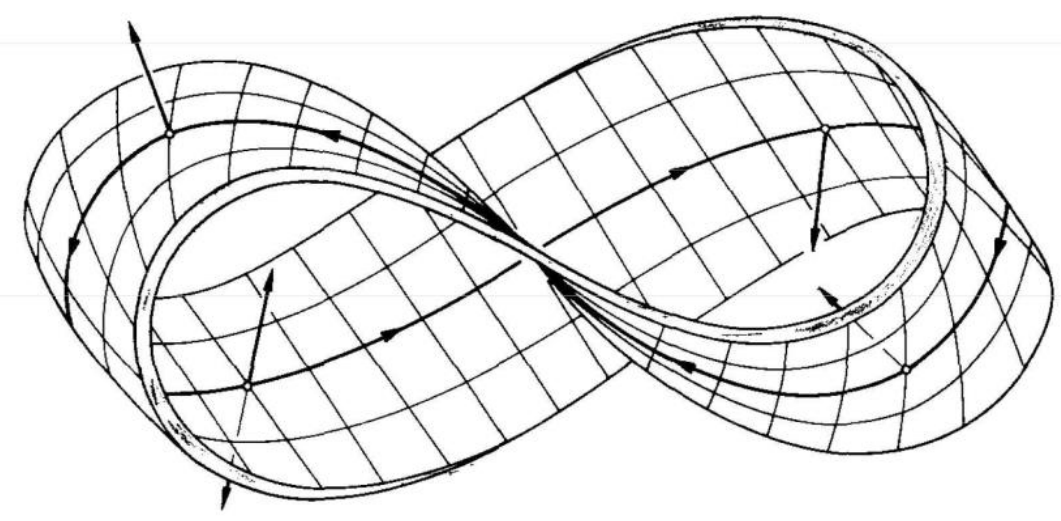

Figure 2. Moebius Strip (Sheng, 2017).

As seen in Figure 2, The Moebius strip is formed by putting together the opposite sides of a strip with a twist. Thanks to that twist, the outside of the strip leads to the inside of the strip, and vice versa, illustrating the overlaps between the conscious and the unconscious. Hence, the Moebius strip illustrates the topological representation of the relation between the conscious and the unconscious in language. If, at one instance, a subject's speech is based on his conscious, with a twist, the unconscious can take over and start informing the subject's language. (Lacan, 1998) Therefore, the unconscious in language can be traced by listening to what the subject is uttering. What, then, can we identify, at the intersection of the conscious and the unconscious?

Through slips of tongue, spoonerisms, pauses, stumblings, ambiguous phrasing, equivoques, double and triple entendres, negations, slurs, stuttering, mumblings, malapropisms or garbled speech, repressed desires in the unconscious are revealed in language (Fink, 1997, p. 6). Speech which fluctuates in volume, changes to the narrative style and the subject's choice of words have also been named by Lacan as unconscious elements. This phenomenon is referred to as a return of the repressed (Lacan, 1966/2006a). These phenomena are all significant moments portraying the reverse of the unconscious in language and they can be studied during the analytic process. 
Psychoanalysis sessions led by the authors of this article provide supporting evidence that the language used by patients reflect their unconscious. As a comprehensive example referring to the first repression, the authors of the article draw on their experiences of conducting psychoanalysis sessions. A young female patient who lived with her family signed up for therapy, complaining that she could "no longer handle things' 2 . In the first session, she talked about the existence of an inner voice and her inner voice said to her: 'Everybody does it, why can't you?'. When the therapist asked what the patient's inner voice meant, the patient started to cry and talked about the bad relationships of her mother and her father. After this point, the main agenda of the sessions was the patient's relationship with the father. Throughout the sessions, the patient mostly talked about her father and started crying after using the word 'father'. She said 'I could not speak to anyone about my father because they would judge me'. When these issues were elaborated, she stated that she was afraid because others would judge her father due to his alcohol problems. Her accounts were therefore vague and inconsistent, since she seemed to suggest that both herself and her father could face judgment, without explaining why she herself could be judged. It is at this stage when the psychoanalysts supervising the session suspected incestuous desires. The patient did not talk much about her mother in the sessions except to describe the times when her mother was not home. She mentioned that her relationship with her father improved when her mother was not home. She explained: 'My dad starts acting weird whenever my mother returns home'. In the sessions, it was thought that the patient felt guilty due to the repressed oedipal desire and it was observed that the desire for the father had a place in the patient's language as well: 'I do not see him as a father', 'I cannot accept my father's preferences', ${ }^{3}$, and 'I want him to think of me as I think of him'. When the psychotherapist reassured the patient that the two-person relationship her mum and dad had contained an important third (the patient herself), the patient resented the idea that she was a mere third participant in a two-person relationship. She started crying and asked 'Why is he cheating on me/making me cry (sic) so much?', referring to her relationship with her father. The sentence she uttered was phonetically ambiguous as to whether the patient said 'making me cry' or 'cheating on me'. In Turkish, the words signifying 'making someone cry' ('ağlatmak') and 'cheating' ('aldatmak') sound similar, hence the phonetic ambiguity. This can be given as an example of metonymy. In the patient's unconscious, these two signifiers which differ in meaning are nonetheless located in the same signifier network, by way of association. This example of metonymy is interpreted as the patient's reaction to triangulation and is regarded as the repressed oedipal desire.

The unconscious can also be traced through language by way of metaphors. During therapy, when the male patient is unable to answer the therapist's questions, he reacts by saying 'I'm about to break my pencil right now'. This statement can be seen as an example of a metaphor. The patient states that he is very close to breaking the pencil he is holding. He explains that in Turkish this expression also means 'there is nothing left to write about the defendant who has been sentenced to death'. Following this utterance, the patient explains that he regards the therapist to be authoritative, similarly to his dad. He adds that his father always dictates to him

\footnotetext{
${ }^{2}$ In the Turkish language, the word used by the patient ('to handle') has double meanings. It can either mean that the patient cannot cope with aspects of her life, or that she is unable to give someone an erection. The psychoanalyst supervising these sessions had the impression that when the patient used this word, she was referring to the latter meaning of the word, describing her sexual desire towards her father.

${ }^{3}$ When the patient referred to 'preferences', she continued to talk about her father being married to her mother.
}

Language and Psychoanalysis, 2021, 10 (1), 27-35. 
the exact way in which his father should conduct himself and that his father later comments on how he failed to follow the instructions. The patient expresses anger at his father's remarks by saying 'if he knows better, he should do it himself'. However, he adds that he cannot confront his father with these remarks since he respects authority. It can be argued that the patient's ambivalent feelings towards his dad rise to the surface through the 'breaking the pencil' metaphor. The patient's choice of metaphor is thought to illustrate self-punishment for failing in the face of authority. These failures are observed both when he fails to accomplish his father's asks and also when he is unable to answer his therapist's questions.

Another example by which the unconscious can be traced through language is equivoque. A young female patient signed up to therapy due to family relationship issues. She was born into the working class but developed herself and went to high-quality schools. During the sessions, the patient explained that she lived a different life from her family, and she had a job which paid well. The patient said: 'I am economically free', explaining that she is financially independent from her family, thanks to her income. In this example, it was heard semantically that the patient talked about her financial power and therefore, her independence from her family. Whereas she claimed to have economic freedom, the implied meaning was that her freedom was restricted. The word 'economic' is an example of equivoque. At this point, as part of an analytic work, the psychotherapist announced to the patient that she might have restricted freedom, not full freedom as she so claimed. When prompted to consider whether her freedom was restricted, the patient accepted this suggestion and proceeded to explain that she was unable to fulfill her desires because of her loyalty for her family. This interaction exemplifies how equivoque can have two meanings and emerge as a clue from the unconscious.

Another female patient, this time with bulimia, whilst questioning her motives for repetitive overeating and purging, refers to the difficulties she is experiencing with her family, friends and boyfriend. When these problems are probed, the patient frequently uses negations, such as 'I'm not someone who gets lost in her thoughts', 'It's not that something like this would trigger me', 'The experience wasn't serious enough to make me eat and purge' and 'My problems are not that frustrating'. The surfacing of these negations is interpreted as the patient's denial of the intense emotions she felt in response to these difficult experiences. As such, it is thought that, in fact, these negations function as affirmatives.

Another means by which the unconscious can be traced in language is through the slips of tongue. The interpretation of slips of tongue is always based on the patient's own discourse. As an example, a female patient talked about her feelings of exclusion since childhood. She mentioned that she was fed up of being excluded in her relationships. Despite expressing that she was fed up of being excluded in her relationships, the patient's main concern was maintaining these relationships. In one of these sessions, the patient made a slip of tongue by saying "I am absent when I am not excluded". This slip of tongue illustrates that despite suggesting that she is fed up of being excluded in relationships, most of the relationships she enters into is based on feelings of exclusion. When the therapist pointed out her slip of tongue, the patient kept describing how much she suffered because of being excluded and ignored the therapist's comment. Considering all the sessions, it was thought that the patient constructed her relationships based on the feeling of 'exclusion' and chose to engage in these relationships because of the jouissance she derived from being excluded. As such, the patient's statement 'I am absent when I am not excluded' can be argued to reveal the patient's unconscious intent. The above study of slips of tongue provides a practical example as to how such slips can be analysed in clinical settings.

Language and Psychoanalysis, 2021, 10 (1), 27-35. 


\section{Conclusion}

Although Freud, a pioneer, developed the talking cure and demonstrated clues of the unconscious in language, the relationship between the unconscious and language was deeply explored by Lacan. Lacan grounded his clinical practice on studying language. He took Freud's theoretical background as a reference to build his own theories. As such, Lacan prioritized the study of the function of speech, as opposed to studies of ego. Lacan believed that symbols, which are fundamental to civilizations, also shape the subject's unconscious. The subjective truth is pushed to the unconscious due to the parental metaphor and the subjective truth surfaces through the subject's speech. The reinterpreted truth can only be set free when the therapist emphasizes and comments on the significant events in the subject's past. During the subject's speech, the unconscious and conscious are interchanging. They manifest themselves as slips of tongue, metaphors, metonymies, negations and equivoques. These examples can be classified as the traces of unconscious and have been explored in this article through the authors' clinical experiences.

\section{Acknowledgements}

We express our gratitude to anonymous reviewers for their useful feedback on an earlier draft of this paper. We are deeply grateful to Prof. Faruk Gençöz and Prof. Tülin Gençöz who, throughout our doctoral studies, contributed to our growth by sharing their theoretical and clinical expertise. Their mentorship has been invaluable and commendable. Furthermore, we are grateful to Psychoanalyst Dr M. Derya Gürsel who stood by our side on our journey to become psychoanalysts. Finally, we are indebted to Linguist Mr Erk N. Günce who supported us with his knowledge and comments and who proofread the final draft. Thanks to Mr Günce's proficiency in both English and Turkish, the Turkish expressions within the article were aptly conveyed in English.

\section{References}

Fink, B. (1997). A clinical introduction to Lacanian psychoanalysis: Theory and technique. Harvard University Press.

Freud, S. (1910). The origin and development of psychoanalysis. American Journal of Psychology, 21, 181-218.

Freud, S. \& Breuer, J. (2001). Histeri üzerine çalışmalar. (E. Kapkın, Trans.). Payel Yayınevi. (Original work published 1895)

Freud, S. (2002). The everyday life in psychopathology (A. Bell, Trans.). Penguin Books. (Original work published 1901)

Lacan, J. (1993). The seminar of Jacques Lacan: Book III: The psychoses 1955-1956 (R. Grigg, Trans.). W. W. Norton \& Company. (Original work published 1981)

Lacan, J. (1998). The seminar of Jacques Lacan Book XI: The four fundamental concepts of psychoanalysis 1964 (A. Sheridan, Trans.). W. W. Norton \& Company. (Original work published 1973)

Lacan, J. (2002). The seminar of Jacques Lacan XII: Crucial problems for psychoanalysis 1964-1965 (C. Gallagher, Trans.). Karnac Books.

Lacan, J. (2006a). The function and field of speech and language in psychoanalysis. In Écrits (pp. 197-268) (B. Fink, Trans.). W. W. Norton \& Company. (Original work published 1966)

Lacan, J. (2006b). The instances of the letter in the unconscious. In Écrits (pp. 412-441) (B. Fink, Trans.). W. W. Norton \& Company. (Original work published 1966) 
Perron, R. (2017). Psikanalizin Tarihi (I. Ergüden, Trans.) Dost Kültür Kitaplığı. (Original work published 1988)

Sheng, X. (2017, February 20). Möbius strip. Medium.

https://medium.com/designscience/1963-88a359d2f68b 